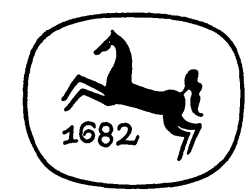

Dilthey und die Hermeneutik 


\section{Dilthey und die Hermeneutik}

Diltheys Begründung der Hermeneutik als 'Praxiswissenschaft` und die Geschichte ihrer Rezeption

\section{INAUGURAL-DISSERTATION}

zur Erlangung des Grades eines Doktors der Philosophie dem Fachbereich Germanistik der Freien Universität Berlin

vorgelegt von

CHRISTOFER ZOOCKLER

aus Wolfshagen 
Als Buchausgabe unter demselben Titel in der J. B. Metzlerschen Verlagsbuchhandlung und Carl Ernst Poeschel Verlag GmbH Stuttgart.

ISBN 978-3-476-99610-7 ISBN 978-3-476-99609-1 (eBook)

DOI 10.1007/978-3-476-99609-1

1. Berichterstatter: Prof. Dr. E. Lämmert

2. Berichterstatter: Prof. Dr. J. Taubes

Tag der mündlichen Prüfung: 7. 7.1975 


\section{Inhalt}

Einleitung ................. . . 1

Warum Dilthey lesen? (S. 1) Zum Begriff Hermeneutik bei Dilthey (S. 3) Arbeitsschritte (S. 12) Wie Dilthey lesen? (S. 14)

Teil I: Entwicklung der diltheyschen Theorie aus den Schriften . .

Der erste Entwurf eines Systems in den Tagebuchaufzeichnungen von 1859 (S. 19)

Von den Tagebüchern zur "Einleitung in die Geisteswissenschaften «. Die Integration der verschiedenen Forschungsansätze in ein System (S. 24)

a) Schlosser-Aufsatz (S. 24)

b) "Ethik« (S. 30)

Analytisches und synthetisches Verfahren bei Kant und Dilthey (S. 34) Exkurs: Die Ethik Kants (S. 35) Apriori, innere Erfahrung und Aufbau der Ethik bei Kant und Dilthey (S. 37) Die Psychologie in Diltheys Ethik (S. 39) Die Stellung der »Ethik« im Aufbau des hermeneutischen Systems (S. 40)

c) Abhandlung von 1875 (S. 44)

»Einleitung in die Geisteswissenschaften " (S. 53)

a) Aufbau der Geisteswissenschaften (S. 54)

b) Individuum, Staat und geschichtliche Entwicklung in der "Einleitung" (S. 59)

c) Die Stellung der "Einleitung" im Entstehungszusammenhang des 'Systems der Geisteswissenschaften (S. 62)

Pläne zur Fortsetzung der "Einleitung in die Geisteswissenschaften " (S. 64)

"Der Aufbau der geschichtlichen Welt in den Geisteswissenschaften ". Versuch eines hermeneutischen Neuansatzes (S. 68)

Exkurs: "Gemeinsamkeit" (Dilthey) und "Umgangssprache" (Habermas) (S. 72)

Zusammenfassung: Diltheys hermeneutische Begründung der Geisteswissenschaften als Praxiswissenschaft (S. 73)

Subjekt und Objekt - historische Substanz und erkennendes Bewußtsein (S. 74) Theorie und Praxis (S. 75) Dilthey und der historische Materialismus - gleiche Probleme, unterschiedliche Lösungen (S. 76) 
Teil II: Zur Geschichte der Dilthey-Rezeption . . . . . . . . .

Natur- und Geisteswissenschaften: Methodendualismus oder Einheitswissenschaft? (S. 80)

Geisteswissenschaften und Sozialwissenschaften, Positivismus und "Anti «Positivismus (S. 87)

a) Geisteswissenschaften (S. 88)

b) Sozialwissenschaften (S. 97)

Historischer Materialismus versus bürgerliche Wissenschaft (S. 104)

Neue Impulse der Dilthey-Rezeption (S. 105)

a) Liebers wissenssoziologische Dilthey-Kritik im Vergleich mit der historisch-materialistischen Ideologiekritik Lukacs' (S. 107)

b) Gadamer (S. 116)

Exkurs: Gadamers Theorie der universalen Hermeneutik (S. 116) Gadamers Dilthey-Kritik (S. 124) Gadamers »anti«-positivistisches Programm der Geisteswissenschaften (S. 131)

c) Habermas (S. 139)

Zur Aktualität der Kritischen Theorie (S. 139) Habermas' Programm einer Synthese von Dilthey und Marx (S. 142) Exkurs: Habermas' Marx-Kritik (S. 144) Habermas' Gadamer-Rezeption (S. 149) Habermas' Dilthey-Rezeption (S. 160)

d) Zur gegenwärtigen Situation der Hermeneutik (S. 164)

Vorbemerkung (S. 164) 1. Bubner (S. 168) 2. Jauß (S. 169) 3. Turk (S. 173) Exkurs: Materialistische Hermeneutik (S. 177)

Teil III: Versuch einer historisch-materialistischen Dilthey-Interpretation

Vorbemerkung (S. 181)

Die shistorische Wende in der Dilthey-Rezeption (S. 182)

a) Herrmann (S. 182)

b) Peschken (S. 184)

Historisch-materialistische Dilthey-Interpretation als Geschichte seiner Teilnahme am Klassenkampf (S. 194)

a) Revolution und Reaktion in Nassau (S. 194)

Exkurs: Die Klassenposition der Diltheys und ihrer Ideologie vor dem Hintergrund der geschichtlichen Entwicklung Nassaus (S. 196)

b) Reaktion in Baden. Klassenkampf im kirchlichen Gewand (S. 199)

1. Vorbemerkung (S. 199) 2. Kuno-Fischer-Konflikt (Diltheys erste Zuwendung zum Liberalismus als Abwendung von der feudalreaktionären politischen Praxis der Kirche) (S. 200) 3. Gervinus-Konflikt (S. 206)

c) Reaktion und Neue Ara in Preußen. Diltheys Abkehr von der theologischen und die Begründung der geisteswissenschaftlichen Hermeneutik (S. 209)

1. Diltheys politisches und fachliches Interesse an einem Studium in Berlin (S. 209) 2. Erste Grundlagen der geisteswissenschaftlichen Hermeneutik [(a) »Wahrheiten« und "Regeln«: Die Verbindung von 
Theorie und Praxis. - (b) Kulturwissenschaften und Wissenschaften von den "gesellschaftlichen Verbänden "] (S. 212) 3. Die Bedeutung der "historischen" und der "philologischen" Methode für Diltheys Begründung der geisteswissenschaftlichen Hermeneutik (S. 216) 4. Zur Vorgeschichte des Diltheyschen Individualitätsbegriffs (Individualismus als Pathologie und seine UUberwindung durch Entsagung [Heine und Goethe]) (S. 223)

d) Reichsgründung und Klassenkompromiß (S. 227)

1. Zusammenfassung: Diltheys Politisierung bis 1866 (S. 227) 2. Dilthey in Basel. Interpretation der Antrittsvorlesung (Der Zusammenhang zwischen Diltheys Sicht der politisch-geistigen Entwicklung in Deutschland und der Herausbildung der wahrhaft historischen Methode: Diltheys politisierte Hermeneutik) (S. 229) Exkurs: Typische Positionen der Klassik-Rezeption im 19. Jahrhundert (S. 235) 3. Die liberalen Antriebe zu einer politisch-historischen Hermeneutik (S. 236) 4. Staat und Kultur: Die säkularisierte 2-Reiche-Lehre (S. 239)

Zusammenfassung: Diltheys Verhältnis zum Staat (S. 239)

Diltheys Verhalten zur Kirche. Exemplarischer Begriff der Kirche als Kultursystem (S. 240)

Uberblick über die kirchenpolitischen Fraktionen (S. 240) Diltheys Reaktion auf die politische und kirchenpolitische Entwicklung in Preußen 1857-1866 (S. 242) Dilthey und die kirchenpolitischen Kämpfe in Preußen und Baden (S. 244) Die christlichliberale Praxis des Protestantenvereins (S. 246) [1. Exkurs: Richard Rothes Theorie eines säkularisierten Christentums in einem christlichen Kulturstaat (S. 246) 2. Rothes Liberalismus im Verhalten zu Kirche und Staat (S. 247) 3. Die Gründung des Protestantenvereins (S. 249)] Diltheys Distanz zu den KirchlichLiberalen (S. 250)

Staat, gesellschaftliche Organisationen und kulturelle Systeme. Diltheys Verzicht auf die demokratischen Rechte am Beispiel der kirchlichen Betätigung (S: 251)

Staatliche Macht und kulturelle Freiheit des Individuums. Die grundlegende Aporie der diltheyschen Hermeneutik (Diltheys sschüchterne, Distanz zum preußisch-deutschen Militarismus. Auseinandersetzung mit Treitschke) (S. 254)

Anhang

Literatur . . . . . . . . . . . . 265

Personenregister. . . . . . . . . . . . . . . 281

Sachregister . . . . . . . . . . . . . 286 